\title{
Caracterização da vegetação de restinga da RPPN de Maracaípe, PE, Brasil, com base na fisionomia, flora, nutrientes do solo e lençol freático
}

\author{
Eduardo Bezerra de Almeida Jr. ${ }^{1,2}$, Murielle Andreo Olivo ${ }^{1}$, Elcida de Lima Araújo ${ }^{1}$ e Carmen Silvia Zickel ${ }^{1}$
}

Recebido em 7/12/2007. Aceito em 27/03/2008

\begin{abstract}
RESUMO - (Caracterização da vegetação de restinga da RPPN de Maracaípe, PE, Brasil, com base na fisionomia, flora, nutrientes do solo e lençol freático). O objetivo deste estudo foi realizar o levantamento florístico e descrever as fisionomias, relacionando-as com as formas de vida, fertilidade do solo e variações do lençol freático encontradas na restinga de Maracaípe. Aárea possui 76,2 ha de vegetação de restinga, sob as coordenadas $08^{\circ} 31^{\prime} 48^{\prime \prime}$ e e 3501'05"W. Possui clima do tipo As' e solo classificado como Neossolo Quartzarênico. Foram feitas caminhadas aleatórias nas três fisionomias existentes - floresta, campo não inundável e campo inundável, durante o período de julho/2003 a julho/2005, para coleta de material botânico. A lista florística foi comparada a outras listas de restinga da região Nordeste. Foram inventariadas 187 espécies, 148 gêneros, distribuídas em 71 famílias. Entre as famílias mais representativas, destacam-se: Poaceae (13 espécies), Cyperaceae (12), Myrtaceae (10), Orchidaceae (9), Rubiaceae (8), Bromeliaceae e Fabaceae (7). A forma de vida "fanerófito" foi elevada na fisionomia florestal e as formas "caméfito", "terófito" e "criptófito", nas fisionomias campo inundável e não inundável. Os solos das fisionomias diferiram quanto à composição química e só ocorreu afloramento do lençol freático na fisionomia campo inundável. Este estudo permitiu concluir que a proporção de formas de vida, variação no nível do lençol freático, matéria orgânica e teor de alumínio no solo foram determinantes na separação das fisionomias da restinga de Maracaípe.
\end{abstract}

Palavras-chave: campo inundável, campo não inundável, floresta, forma de vida, vegetação costeira

\begin{abstract}
Characterization of restinga vegetation at Maracaípe, Pernambuco State, Brazil, based on physiognomy, flora, soil nutrients, and water-table level). We undertook a floristic survey to describe the phytophysiognomies of a restinga at Maracaípe, and related these to life form, soil fertility, and variation in the local water-table level. The study area is located at $08^{\circ} 31^{\prime} 48^{\prime \prime} S$ and $35^{\circ} 01^{\prime} 05^{\prime \prime} \mathrm{W}$, and has 76.2 ha of restinga vegetation. The regional climate is classified as As' and local soils are sandy Neosols. Random walks to collect botanical material were made in the three different vegetation physiognomies found in the area - forest, flooded grassland and non-flooded grassland - from July/2003 to July/2005. The resulting list of plant species was compared to other restinga areas of Northeast Brazil. A total of 187 species belonging to 148 genera and 71 families were found in the survey area. The families best represented were Poaceae (13 species), Cyperaceae (12), Myrtaceae (10), Orchidaceae (9), Rubiaceae (8), Bromeliaceae and Fabaceae (7). Phanerophytes were well represented in the forest, while camephytes, therophytes, and cryptophytes were best represented in the flooded grassland and non-flooded grassland. The soils of the different vegetation physiognomies differed in terms of chemical composition, and the water table reached the soil surface only in the flooded grassland. We conclude that different proportions of life form, variation in water-table levels, and soil organic matter and aluminum content were determining factors for segregating the different plant physiognomies in the Maracaípe restinga.
\end{abstract}

Key words: coastal vegetation, flooded grassland, forest, life form, non-flooded grassland

\section{Introdução}

A fisionomia da vegetação reflete a disposição, o arranjo e as relações entre os indivíduos que constituem a comunidade vegetal (Martins 1991). Tais características podem variar dentro de uma mesma formação vegetacional, sobretudo se esta ocupar extensas áreas com heterogeneidade de condições ambientais. Entre tais formações, destaca-se a restinga, considerada por Suguio \& Tessler (1984) como uma vegetação que se desenvolve sobre depósitos litorâneos que formam extensas planícies arenosas quaternárias, ocorrendo desde dunas até as planícies costeiras, cujas fisionomias variam desde o tipo herbáceo reptante praiano até floresta fechada (Oliveira Filho \& Carvalho 1993).

Veloso (1992) classificou as áreas litorâneas do Brasil como vegetação pioneira com influência marinha (restinga), dando destaque aos tipos arbóreo, arbustivo e herbáceo. Contudo, esta classificação não vem sendo adotada devido às diferenças existentes quanto ao conjunto florístico e ao arranjo estrutural das populações nas distintas áreas de restinga ao longo da costa brasileira

\footnotetext{
1 Universidade Federal Rural de Pernambuco, Rua Dom Manoel de Medeiros s.n., Dois Irmãos, 52171-900 Recife, PE, Brasil

2 Autor para correspondência: ebaj25@yahoo.com.br
} 
(Araujo \& Henriques 1984; Sá 1992; Menezes \& Araujo 1999). Atualmente, as fisionomias de restinga do sul e sudeste do País vêm sendo denominadas de "scrub de Clusia", "thicket de Myrtaceae", "campo", "fruticeto" e "floresta" (Araujo \& Henriques 1984; Assis et al. 2004; Silva \& Britez 2005). As duas primeiras são mais adotadas na região sudeste para as formações arbustivo-arbóreas e dão destaque, principalmente, à espécie de elevada representatividade no arranjo estrutural (Zaluar \& Scarano 2000). As três últimas contemplam o conjunto florístico dominante, o espaçamento existente entre as plantas e a ocorrência de alagamento (variação do lençol freático) (Silva \& Britez 2005).

No Nordeste, Andrade-Lima (1960) reconheceu a vegetação da restinga como um tipo de vegetação da zona do litoral, podendo ser subdividida em mata de restinga e campo de restinga. $\mathrm{O}$ critério adotado pelo autor em sua classificação foi exclusivamente florístico. Contudo, os estudos de florística e de fitossociologia desenvolvidos nesse ecossistema a partir do ano 2000 (Zickel et al. 2004; Medeiros et al. 2007; Zickel et al. 2007; Sacramento et al. 2007; Silva et al. 2008) reúnem evidências mostrando que as terminologias de fisionomias propostas por Silva \& Britez (2005), ou seja, campo, fruticeto e floresta, são mais adequadas e flexíveis para classificar as restingas até o momento estudadas no Nordeste, devido à baixa ocorrência de Clusiaceae e de Myrtaceae, que se destacam nas fisionomias "scrub" e "thicket" das restingas do Sudeste. Além disso, a proposta de Silva \& Britez (2005) também considera a influência da variação do lençol freático e do nível de sobreposição de copas na estrutura da vegetação, que não foram contempladas na classificação de AndradeLima (1960).

Apesar da adequação da classificação de Silva \& Britez (2005), a freqüência dos tipos fisionômicos não é homogênea nas restingas do Nordeste (C.S. Zickel, dados não publicados). De uma maneira geral, a diversidade de espécies na restinga é considerada elevada (Zickel et al. 2007), porém, inexistem estudos direcionados a identificar grupos de espécies ou formas de vida exclusivas das distintas fisionomias, bem como o papel da variação do lençol freático e do teor de nutrientes do solo no arranjo estrutural das populações.

Se a fisionomia da vegetação reflete a disposição, o arranjo e a composição de espécies da comunidade, espera-se identificar diferenças na florística e na proporção de formas de vida entre os tipos fisionômicos presentes nas diferentes restingas do litoral brasileiro. Considerando que a variação do lençol freático proporciona alagamento sazonal entre áreas de restinga, espera-se encontrar diferenças na composição de espécies e nas características dos solos que permitam mostrar como o lençol freático pode influenciar no arranjo florístico desses ecossistemas.

Diante do exposto, este estudo teve como objetivo realizar um levantamento florístico de uma área de restinga em Maracaípe, Pernambuco, direcionado a responder as seguintes perguntas: A área é homogênea quanto aos tipos fisionômicos? Existindo diferenças de fisionomia, as mesmas mantêm diferenças na composição de espécies e de formas de vida? Características do solo e variações no nível do lençol freático são variáveis que permitem distinguir diferenças florísticas na área?

\section{Material e métodos}

Área de estudo - A Reserva Particular do Patrimônio Natural (RPPN) Nossa Senhora do Outeiro de Maracaípe (IBAMA 2000) localiza-se no litoral sul de Pernambuco, município de Ipojuca, sob as coordenadas $08^{\circ} 31^{\prime} 48^{\prime \prime} \mathrm{S}$ e $35^{\circ} 01^{\prime} 05^{\prime}$ 'W e ocupa uma área de 76,2 ha sobre planície litorânea. Dessa área, 60,96 ha correspondem a vegetação de restinga e 15,24 ha correspondem a vegetação de manguezal, que ocorre margeando a restinga. A área dista cerca de $5 \mathrm{~km}$ do mar e, de maneira geral, apresenta relevo plano, com suaves ondulações. O solo é constituído por Neossolos Quartzarênicos e, apesar de não existir lagoas perenes na área, alguns trechos do solo podem ficar inundados durante o período chuvoso. O clima, segundo a classificação de Köppen (1948), é do tipo As' tropical chuvoso, com verão seco e menos de $60 \mathrm{~mm}$ de chuva no mês mais seco, com precipitação pluviométrica anual aproximada de $2.000 \mathrm{~mm}$. A estação chuvosa ocorre de abril a setembro, sendo os meses de maio, junho e julho os mais chuvosos; a estação seca vai de outubro a março, sendo os meses de outubro, novembro e dezembro os mais secos (INMET 2005).

A vegetação de restinga apresenta fisionomias dos tipos floresta e campo (inundável e não inundável), com pouca deciduidade ao final da estação seca (Medeiros et al. 2007) e sem dominância aparente de uma espécie na composição florística. De acordo com a classificação proposta por Silva \& Britez (2005), a fisionomia "floresta" apresenta predominância de árvores com estratos diferenciados e as fisionomias "campo inundável" e "campo não inundável" apresentam predominância de plantas herbáceas. O campo não inundável representa a área do solo que permanece livre do acúmulo de água, e o campo inundável representa a área do solo que permanece periodicamente inundada, devido ao afloramento do lençol freático. No campo não inundável, ocorrem ondulações no relevo, atingindo, em alguns trechos, até $0,5 \mathrm{~m}$ de altura.

Por se tratar de uma de propriedade particular, a vegetação apresenta poucos indícios de pressão 
antrópica, ocorrendo pouquíssimos indivíduos com evidências de corte, na fisionomia floresta. Nas fisionomias de campo inundável e de campo não inundável, não foi observado nenhum indício de ação antrópica. Portanto, de uma maneira geral, a área de estudo apresenta bom estado de conservação, apesar de população local transitar pela área.

Florística e classificação das formas de vida - Foram realizadas visitas mensais, no período de julho/2003 a julho/2005, para coleta de material botânico fértil, através de caminhadas por trilhas existentes e novas trilhas implantadas a fim de aumentar a intensidade de coleta. Para identificar o conjunto florístico presente nos diferentes estratos das fisionomias, foi feita uma estimativa da altura de algumas plantas, com auxílio de uma vara graduada.

O material processado seguiu a metodologia usual de Mori et al. (1989) e foi incorporado no Herbário IPA - Dárdano de Andrade Lima. A listagem das espécies seguiu o sistema de classificação de Cronquist (1988) e a identificação foi feita com o auxílio de literatura especializada: Maas \& Westra (1992), Lorenzi (1992; 1998), Miranda \& Giulietti (2001), Barreto (2002), Furlan \& Machado (2002), Rodrigues \& Rossi (2002), Skorupa (2003), Souza \& Sales (2004), Pontes et al. (2004) e Pereira \& Barbosa (2004), além da comparação com material do acervo dos herbários IPA e Professor Vasconcelos Sobrinho - PEUFR, sendo posteriormente confirmada por especialistas.

As principais formas de vida existentes em cada fisionomia foram identificadas com base no sistema de classificação de Raunkiaer (1934). Para isto, durante a estação desfavorável (estação seca), foi observado se os indivíduos das espécies permaneciam vivos na área, se lançavam sementes no solo e morriam, ou se perdiam o sistema aéreo, mas mantinham gemas, bulbos ou rizomas no solo, ou abaixo deste, que permitisse a regeneração da população. Assim, quando necessário foram feitas escavações na base da planta.

Distribuição das espécies - Para verificar se as espécies da restinga de Maracaípe ocorriam em outras restingas do Nordeste, foram consultados os seguintes levantamentos florísticos: Andrade-Lima (1951; 1954; 1979), Sacramento et al. 2007, J.R. Cantarelli (restinga de Guadalupe, dados não publicados) e Silva et al. (2008) para Pernambuco; R.F. Rocha (Piaçabuçu, dados não publicados) e Esteves (1980) para Alagoas; Pinto et al. (1984) e Meira Neto et al. (2005) para a Bahia; Matias \& Nunes (2001) para o Ceará; Oliveira Filho \& Carvalho (1993), Oliveira Filho (1993) para a Paraíba; CabralFreire \& Monteiro (1993) para o Maranhão; e Freire (1990) para o Rio Grande do Norte.
Análises do solo - Para as análises químicas e granulométricas do solo, foram coletadas cinco amostras em cada fisionomia, a uma profundidade de $20 \mathrm{~cm}$, de acordo com as recomendações da EMBRAPA (1999). As análises foram realizadas por especialistas do Laboratório de Solos do Departamento de Agronomia da UFRPE, seguindo protocolo da EMBRAPA (1997). As variáveis de solo medidas foram: $\mathrm{P}, \mathrm{K}, \mathrm{Ca}, \mathrm{C}, \mathrm{Mg}, \mathrm{Al}$, $\mathrm{H}+\mathrm{Al}, \mathrm{Fe}, \mathrm{Mn}, \mathrm{Zn}$; soma de bases (S), saturação por bases $(\mathrm{V})$, percentagem de sódio trocável (PST), saturação por alumínio $(\mathrm{m})$; matéria orgânica e teores de areia, silte e argila.

Variação do lençol freático - Para o acompanhamento da dinâmica do lençol freático ao longo dos períodos seco e chuvoso, foram realizadas quatro perfurações na área, sendo três na fisionomia floresta (L1, L2, L3) e uma na fisionomia campo inundável (L4). Os três poços da floresta foram alinhados na direção do manguezal. O primeiro (L1) distou cerca de $500 \mathrm{~m}$ da área do manguezal, visando evitar a influência deste na variação do lençol freático. Os demais poços (L2 e L3) distaram $400 \mathrm{~m}$ entre si, a partir do primeiro. As perfurações foram feitas com o auxílio de um trado (com $3 / 4$ de polegada e de $6 \mathrm{~m}$ compr.), sendo, posteriormente, introduzidos no solo tubos de PVC com diâmetro de $40 \mathrm{~mm}$ e $3 \mathrm{~m}$ compr., visando evitar o desmoronamento das paredes internas do poço. Os tubos de PVC foram perfurados, envoltos por uma malha de nylon, para facilitar a percolação da água e evitar a entrada de areia, e foram vedados com tampões na parte superior, para evitar a entrada de água da chuva.

O nível do lençol freático foi medido uma vez por mês, durante 17 meses (março/2004 a julho/2005). A altitude da área, em cada poço perfurado, foi determinada com um altímetro de precisão, para verificar os possíveis desníveis do terreno.

Análises estatísticas - As variações no lençol freático e as variáveis do solo amostrados em relação às fisionomias da restinga foram analisadas através do teste não paramétrico Mann-Whitney (Ayres et al. 2000), a $5 \%$ de probabilidade, com normalidade testada através do teste Kolmogorov-Smirnov (Ayres et al. 2000).

\section{Resultados}

Foram amostradas 186 espécies, distribuídas em 148 gêneros e 71 famílias (Tab. 1). As famílias mais representativas em número de espécies foram: Poaceae (13 espécies), Cyperaceae e Myrtaceae (12), Orchidaceae e Rubiaceae (9), Bromeliaceae e Fabaceae (7), Mimosaceae e Caesalpiniaceae (6), Euphorbiaceae (5), Annonaceae e Chrysobalanaceae (4), correspondendo a 50,26\% das espécies. 
Tabela 1. Espécies amostradas na restinga da RPPN - Nossa Senhora do Outeiro de Maracaípe, Ipojuca, PE, Brasil. Formas de vida: Fan - fanerófito; Cam - caméfito; Ter - terófito; Crp - criptófito; Hmc - hemicriptófito; Trp - trepadeira e Epf - epífito. Fisionomia: CNI - campo não inundável; CI - campo inundável; FNI - floresta não inundável.

\begin{tabular}{|c|c|c|c|c|c|}
\hline \multirow[t]{2}{*}{ Famílias/Espécies } & \multirow[t]{2}{*}{ Coletor/Número } & \multirow[t]{2}{*}{ Forma de vida } & \multicolumn{3}{|c|}{ Fisionomia } \\
\hline & & & $\mathrm{CNI}$ & CI & FNI \\
\hline \multicolumn{6}{|l|}{ ACANTHACEAE } \\
\hline Ruellia geminiflora Kunth & M.A. Olivo, 69 & Cam & $\mathrm{x}$ & & \\
\hline \multicolumn{6}{|l|}{ ANACARDIACEAE } \\
\hline Anacardium occidentale L. & E.B. Almeida, 474 & Fan & $\mathrm{x}$ & $\mathrm{x}$ & $\mathrm{x}$ \\
\hline Schinus terebinthifolius Raddi & E.B. Almeida, 426 & Fan & $\mathrm{x}$ & & $\mathrm{x}$ \\
\hline Tapirira guianensis Aubl. & E.B. Almeida, 388 & Fan & & & $\mathrm{x}$ \\
\hline \multicolumn{6}{|l|}{ ANNONACEAE } \\
\hline Annona crassiflora Mart. & E.B. Almeida, 333 & Fan & $\mathrm{x}$ & & $\mathrm{x}$ \\
\hline A. montana Macfad. & E.B. Almeida, 464 & Fan & & & $\mathrm{x}$ \\
\hline Rollinia pickelii Diels & E.B. Almeida, 432 & Fan & & & $\mathrm{x}$ \\
\hline Xylopia laevigata (Mart.) R.E. Fr. & E.B. Almeida, 439 & Fan & & & $\mathrm{x}$ \\
\hline \multicolumn{6}{|l|}{ APOCYNACEAE } \\
\hline Hancornia speciosa Gomes & E.B. Almeida, 360 & Fan & $\mathrm{x}$ & & $\mathrm{x}$ \\
\hline Himatanthus phagedaenicus (Mart.) Woodson & E.B. Almeida, 390 & Fan & & & $\mathrm{x}$ \\
\hline Mandevilla scabra (Hoffmanns ex Roem. \& Schult.) K. Schum. & E.B. Almeida, 402 & Trp & & & $\mathrm{x}$ \\
\hline \multicolumn{6}{|c|}{ ARACEAE } \\
\hline Anthurium affine Schott & E.B. Almeida, 340 & $\mathrm{Hmc}$ & & & $\mathrm{x}$ \\
\hline Anthurium sp. & E.B. Almeida, 710 & Epf & & & $\mathrm{x}$ \\
\hline Philodendron imbe Schott & M.A. Olivo, 151 & Trp & & & $\mathrm{x}$ \\
\hline Zonicarpa pythonium (Mart.) Schott & M.A. Olivo, 115 & Ter & & & $\mathrm{x}$ \\
\hline \multicolumn{6}{|l|}{ ARECACEAE } \\
\hline Bactris humilis (Wallace) Burret & M.A. Olivo, 84 & Fan & & & $\mathrm{x}$ \\
\hline \multicolumn{6}{|l|}{ ASCLEPIADACEAE } \\
\hline Ditassa crassifolia Decne. & E.B. Almeida, 408 & Trp & & & $\mathrm{x}$ \\
\hline \multicolumn{6}{|l|}{ ASTERACEAE } \\
\hline Conyza bonariensis (L.) Cronquist & M.A. Olivo, 68 & Ter & $\mathrm{x}$ & & \\
\hline Elephantopus hirtiflorus DC. & E.B. Almeida, 362 & Ter & $\mathrm{x}$ & & \\
\hline Platypodanthera melissaefolia (DC.) R.M. King \& H. Rob. & M.A. Olivo, 109 & Ter & $\mathrm{x}$ & & \\
\hline \multicolumn{6}{|l|}{ BORAGINACEAE } \\
\hline Tournefortia candidula (Miers) I.M. Johnston & E.B. Almeida, 463 & Fan & & & $\mathrm{x}$ \\
\hline \multicolumn{6}{|l|}{ BROMELIACEAE } \\
\hline Aechmea tomentosa Mez & E.B. Almeida, 520 & $\mathrm{Hmc}$ & & & $\mathrm{x}$ \\
\hline Bromelia karatas $\mathrm{L}$. & M.A. Olivo, 120 & $\mathrm{Hmc}$ & & & $\mathrm{x}$ \\
\hline Cryptanthus burle-marxii Leme & E.B. Almeida, 537 & $\mathrm{Hmc}$ & & & $\mathrm{x}$ \\
\hline Cryptanthus sp. & M.A. Olivo,133 & $\mathrm{Hmc}$ & & & $\mathrm{x}$ \\
\hline Hohenbergia ramageana $\mathrm{Mez}$ & M.A. Olivo, 152 & $\mathrm{Hmc}$ & & & $\mathrm{x}$ \\
\hline H. ridleyi (Baker) Mez & A.L. Almeida, 16 & $\mathrm{Hmc}$ & & & $\mathrm{x}$ \\
\hline Portea leptantha Harms & E.B. Almeida, 449 & $\mathrm{Hmc}$ & & & $\mathrm{x}$ \\
\hline \multicolumn{6}{|l|}{ BURSERACEAE } \\
\hline Protium heptaphyllum (Aubl.) Marchand & E.B. Almeida, 396 & Fan & & & $\mathrm{x}$ \\
\hline \multicolumn{6}{|l|}{ CACTACEAE } \\
\hline Cereus fernambucensis Lem. & M.A. Olivo, 98 & Fan & & & $\mathrm{x}$ \\
\hline \multicolumn{6}{|l|}{ CAESALPINIACEAE } \\
\hline Chamaecrista ensiformis (Vell.) H.S. Irwin \& Barneby & E.B. Almeida, 339 & Fan & & & $\mathrm{x}$ \\
\hline C. flexuosa (L.) Greene & M.A. Olivo, 81 & Ter & $\mathrm{x}$ & $\mathrm{x}$ & $\mathrm{x}$ \\
\hline C. ramosa (Vogel) H.S. Irwin \& Barneby & M.A. Olivo, 62 & Ter & $\mathrm{x}$ & & \\
\hline C. repens (Vogel) H.S. Irwin \& Barneby & M.A. Olivo, 80 & Ter & $\mathrm{x}$ & & \\
\hline C. rotundifolia (Pers.) Greene & M.A. Olivo, 66 & Ter & $\mathrm{x}$ & & \\
\hline Senna macranthera (DC. ex Collad.) H.S. Irwin \& Barneby & E.B. Almeida, 357 & Fan & & & $\mathrm{x}$ \\
\hline CAPPARACEAE & & & & & \\
\hline Capparis flexuosa (L.) L. & E.B. Almeida, 411 & Fan & & & $\mathrm{x}$ \\
\hline CECROPIACEAE & & & & & \\
\hline Cecropia pachystachya Trécul & E.B. Almeida, 728 & Fan & & & $\mathrm{x}$ \\
\hline CELASTRACEAE & & & & & \\
\hline Maytenus distichophylla Mart. & E.B. Almeida, 430 & Fan & & & $\mathrm{x}$ \\
\hline CHRYSOBALANACEAE & & & & & \\
\hline Couepia rufa Ducke & E.B. Almeida, 497 & Fan & & & $\begin{array}{c}\mathrm{x} \\
\text { continua }\end{array}$ \\
\hline
\end{tabular}


Tabela 1 (continuação)

\begin{tabular}{|c|c|c|c|c|c|}
\hline \multirow[t]{2}{*}{ Famílias/Espécies } & \multirow[t]{2}{*}{ Coletor/Número } & \multirow[t]{2}{*}{ Forma de vida } & \multicolumn{3}{|c|}{ Fisionomia } \\
\hline & & & $\mathrm{CNI}$ & $\mathrm{CI}$ & FNI \\
\hline Hirtella racemosa Lam. & E.B. Almeida, 504 & Fan & & & $\mathrm{x}$ \\
\hline Licania dealbata Hook. f. & E.B. Almeida, 538 & Fan & & & $\mathrm{x}$ \\
\hline L. rigida Benth. & E.B. Almeida, 539 & Fan & & & $\mathrm{x}$ \\
\hline \multicolumn{6}{|l|}{ CLUSIACEAE } \\
\hline Calophyllum brasiliense Cambess. & E.B. Almeida, 494 & Fan & & & $\mathrm{x}$ \\
\hline Vismia guianensis (Aubl.) Pers. & E.B. Almeida,542 & Fan & & & $\mathrm{x}$ \\
\hline \multicolumn{6}{|l|}{ COMBRETACEAE } \\
\hline Buchenavia capitata (Vahl.) Eichler & E.B. Almeida, 458 & Fan & $\mathrm{x}$ & & $\mathrm{x}$ \\
\hline Conocarpus erectus $\mathrm{L}$. & E.B. Almeida, 483 & Fan & & & $\mathrm{x}$ \\
\hline \multicolumn{6}{|l|}{ COMMELINACEAE } \\
\hline Commelina obliqua Vahl. & M.A. Olivo, 82 & Ter & $\mathrm{x}$ & $\mathrm{x}$ & \\
\hline Dichorisandra albo-marginata Linden & E.B. Almeida, 418 & Ter & & & $\mathrm{x}$ \\
\hline \multicolumn{6}{|l|}{ CONVOLVULACEAE } \\
\hline Ipomoea marcellia Meisn. & E.B. Almeida, 718 & $\operatorname{Trp}$ & & & $\mathrm{x}$ \\
\hline \multicolumn{6}{|l|}{ COSTACEAE } \\
\hline Costus spiralis (Jacq.) Roscoe & E.B. Almeida, 443 & Crp & & & $\mathrm{x}$ \\
\hline \multicolumn{6}{|l|}{ CYPERACEAE } \\
\hline Abildgaardia scirpoides Nees. & E.B. Almeida, 444 & Cam & $\mathrm{x}$ & & \\
\hline Bulbostylis capillaris (L.) L.B. Clarke & M.A. Olivo, 14 & Ter & $\mathrm{x}$ & $\mathrm{x}$ & \\
\hline Cyperus aggregatus (Willd.) Endl. & M.A. Olivo, 95 & Crp & $\mathrm{x}$ & & \\
\hline C. laxus Lam. & E.B. Almeida, 447 & Crp & $\mathrm{x}$ & & \\
\hline C. meyenianus Kunth. & E.B. Almeida, 446 & Cam & $\mathrm{x}$ & & \\
\hline Eleocharis geniculata (L.) Roem. \& J. Schull. & M.A. Olivo, 77 & Cam & $\mathrm{x}$ & $\mathrm{x}$ & \\
\hline Fimbristylis cymosa R. Brown & M.A. Olivo, 75 & Cam & $\mathrm{x}$ & $\mathrm{x}$ & \\
\hline Fuirena umbellata Rottb. & M.A. Olivo, 15 & Crp & $\mathrm{x}$ & & \\
\hline Pycreus pelophylus (Ridl.) C.B. Clarke & M.A. Olivo, 134 & Ter & & $\mathrm{x}$ & \\
\hline P. polystachyos (Rottb.) P. Beauv. & M.A. Olivo, 28 & Crp & $\mathrm{x}$ & & \\
\hline Rynchospora barbata (Vahl.) Kunth. & M.A. Olivo, 74 & Crp & $\mathrm{x}$ & $\mathrm{x}$ & \\
\hline R. riparia (Ness.) Boeck & M.A. Olivo, 139 & Crp & $\mathrm{x}$ & $\mathrm{x}$ & \\
\hline \multicolumn{6}{|l|}{ DILLENIACEAE } \\
\hline Curatella americana $\mathrm{L}$. & A.L.S. Almeida, 21 & Fan & & & $\mathrm{x}$ \\
\hline Tetracera breyniana Schlechtd. & E.B. Almeida, 356 & Fan & $\mathrm{x}$ & $\mathrm{x}$ & $\mathrm{x}$ \\
\hline \multicolumn{6}{|l|}{ DIOSCOREACEAE } \\
\hline Dioscorea leptostachya Gardner & E.B. Almeida, 708 & $\operatorname{Trp}$ & & & $\mathrm{x}$ \\
\hline D. polygonoides Humb. \& Bonpl. ex Willd. & E.B. Almeida, 353 & Trp & & & $\mathrm{x}$ \\
\hline \multicolumn{6}{|l|}{ ELAEOCARPACEAE } \\
\hline Sloanea guianensis (Aubl.) Benth. & E.B. Almeida, 370 & Fan & & & $\mathrm{x}$ \\
\hline \multicolumn{6}{|l|}{ ERIOCAULACEAE } \\
\hline Eriocaulon palustre Salzm. & M.A. Olivo, 26 & $\mathrm{Hmc}$ & $\mathrm{x}$ & & $\mathrm{x}$ \\
\hline Paepalanthus bifidus (Schrader) Kunth & M.A. Olivo, 12 & $\mathrm{Hmc}$ & $\mathrm{x}$ & & $\mathrm{x}$ \\
\hline P. tortilis (Bong.) Koern. & P.B. Lima, 01 & $\mathrm{Hmc}$ & & & $\mathrm{x}$ \\
\hline \multicolumn{6}{|l|}{ ERYTHROXYLACEAE } \\
\hline Erythroxylum passerinum Mart. & E.B. Almeida, 433 & Fan & & & $\mathrm{x}$ \\
\hline \multicolumn{6}{|l|}{ EUPHORBIACEAE } \\
\hline Chamaesyce thymifolia (L.) Millsp. & M.A. Olivo, 135 & Ter & $\mathrm{x}$ & $\mathrm{x}$ & \\
\hline Croton klotzschii (Didr.) Baill. & E.B. Almeida, 420 & Cam & $\mathrm{x}$ & & $\mathrm{x}$ \\
\hline C. sellowii Baill. & E.B. Almeida, 341 & Cam & $\mathrm{x}$ & & $\mathrm{x}$ \\
\hline Microstachys corniculata (Vahl) Griseb. & E.B. Almeida, 422 & Fan & $\mathrm{x}$ & & \\
\hline Pera glabrata (Schott) Poepp. ex Baill. & E.B. Almeida, 454 & Fan & & & $\mathrm{x}$ \\
\hline FABACEAE & & & & & \\
\hline Andira fraxinifolia Benth. & E.B. Almeida, 489 & Fan & & & $\mathrm{x}$ \\
\hline A. nitida Mart. ex Benth. & E.B. Almeida, 490 & Fan & & & $\mathrm{x}$ \\
\hline Centrosema brasilianum (L.) Benth. & E.B. Almeida, 403 & $\operatorname{Trp}$ & $\mathrm{x}$ & $\mathrm{x}$ & $\mathrm{x}$ \\
\hline Clitoria laurifolia Poir. & M.A. Olivo, 35 & Cam & $\mathrm{x}$ & & \\
\hline Desmodium barbatum (L.) Benth. \& Oerst. & E.B. Almeida, 427 & Fan & $\mathrm{x}$ & & $\mathrm{x}$ \\
\hline Stylosanthes viscosa (L.) Sw. & M.A. Olivo, 45 & Cam & $\mathrm{x}$ & $\mathrm{x}$ & $\mathrm{x}$ \\
\hline Zornia diphylla (L.) Pers. & E.B. Almeida, 419 & Cam & $\mathrm{x}$ & & \\
\hline FLACOURTIACEAE & & & & & \\
\hline Casearia javitensis Kunth & E.B. Almeida, 409 & Fan & & & $\begin{array}{c}\mathrm{x} \\
\text { continua }\end{array}$ \\
\hline
\end{tabular}


Tabela 1 (continuação)

\begin{tabular}{lllll}
\hline Famílias/Espécies & Coletor/Número & Forma de vida & \multicolumn{2}{c}{ Fisionomia } \\
\cline { 3 - 4 } & & $\mathrm{CNI}$ & $\mathrm{FNI}$
\end{tabular}

GENTIANACEAE

Schultesia guianensis (Aulb.) Malme

M.A. Olivo, 85

Ter

$\mathrm{x}$

HYDROPHYLLACEAE

Hydrolea spinosa $\mathrm{L}$.

HUMIRIACEAE

Sacoglottis mattogrossensis Malme

E.B. Almeida, 556

Crp

$\mathrm{x}$

IRIDACEAE

Cipura paludosa Aubl.

Neomarica caerulea (Ker Gawl.) Sprague

E.B. Almeida, 366

Fan

$\mathrm{x}$

E.B. Almeida, 346

M.A. Olivo, 59

Crp

Crp

M.A. Olivo, 27

Hyptis fruticosa Salzm. ex Benth.

H. suaveolens $(\mathrm{L}$.) Poit.

Ocimum gratissimum $\mathrm{L}$.

M.A. Olivo, 30

E.B. Almeida, 348

Fan

Crp

Crp

E.B. Almeida, 685

Ocotea duckei Vattimo

O. gardneri (Meisn.) Mez

E.B. Almeida, 441

Fan

Fan

E.B. Almeida, 431

Fan

Eschweilera ovata (Cambess.) Miers

LENTIBULARIACEAE

Utricularia pusilla Vahl.

E.B. Almeida, 729

Crp

M.A. Olivo, 64

Crp

Hippeastrum stylosum Herb.

LORANTHACEAE

Psittacanthus dichrous (Mart.) Mart.

LYTHRACEAE

Cuphea flava Spreng.

MALPIGHIACEAE

Byrsonima riparia W.R. Anderson

B. sericea DC.

Stigmaphyllon paralias A. Juss.

MALVACEAE

Pavonia cancellata (L.) Cav.

Sida ciliaris L.

S. linifolia Juss. ex Cav

MARANTACEAE

Stromanthe tonckat (Aubl.) Schum.

MARCGRAVIACEAE

Norantea brasiliensis Choisy

MELASTOMATACEAE

Clidemia hirta (L.) D. Don

Miconia albicans (Sw.) Triana

E.B. Almeida, 724

Epf

M.A. Olivo, 01

Cam

E.B. Almeida, 337

E.B. Almeida, 371

E.B. Almeida, 361

Fan

Fan

M.A. Olivo, 04

E.B. Almeida. 701

M.A. Olivo, 99

Cam

Cam

Cam

Fan

M.A. Olivo, 116

Ter

E.B. Almeida, 393

Fan

$\mathrm{X}$

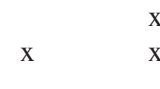

$\mathrm{x}$

M.A. Olivo, 87

E.B. Almeida, 487

Fan

Fan

E.B. Almeida, 467

E.B. Almeida, 462

E.B. Almeida, 336

E.B. Almeida, 670

A.L.S. Almeida, 30

M.A. Olivo, 119

Mimosa somnians Humb. \& Bonpl. ex Willd.

E.B. Almeida, 421

E.B. Almeida, 495

Fan

Fan

Fan

Fan

Fan

Fan

MOLLUGINACEAE

Mollugo verticillata $\mathrm{L}$.

MORACEAE

Ficus guianensis Desv. ex Ham.

MYRSINACEAE

Rapanea guianensis Aubl.

MYRTACEAE

Campomanesia dichotoma (O. Berg) Mattos

Eugenia excelsa $\mathrm{O}$. Berg

E. hirta O. Berg

E. punicifolia (Kunth) DC.

Marlierea regeliana $\mathrm{O}$. Berg

E.B. Almeida, 541

Ter

Fan

$\mathrm{x}$

$\mathrm{x}$

E.B. Almeida, 436

Fan

$\mathrm{X}$

$\mathrm{x}$

$\mathrm{x}$

E.B. Almeida, 691

E.B. Almeida, 352

E.B. Almeida, 414

E.B. Almeida, 639
Fan
Fan

Fan

Fan

Fan

\begin{tabular}{|c|c|}
\hline $\mathrm{x}$ & $\mathrm{x}$ \\
\hline $\mathrm{X}$ & \\
\hline X & \\
\hline
\end{tabular}


Tabela 1 (continuação)

\begin{tabular}{|c|c|c|c|c|c|}
\hline \multirow[t]{2}{*}{ Famílias/Espécies } & \multirow[t]{2}{*}{ Coletor/Número } & \multirow[t]{2}{*}{ Forma de vida } & \multicolumn{3}{|c|}{ Fisionomia } \\
\hline & & & $\mathrm{CNI}$ & $\mathrm{CI}$ & FNI \\
\hline Marlierea sp. 1. & E.B. Almeida, 345 & Fan & & & $\mathrm{x}$ \\
\hline Myrcia bergiana $\mathrm{O}$. Berg & E.B. Almeida, 381 & Fan & $\mathrm{x}$ & $\mathrm{x}$ & $\mathrm{x}$ \\
\hline M. guianensis (Aubl.) DC. & E.B. Almeida, 379 & Fan & & & $\mathrm{x}$ \\
\hline M. hirtiflora DC. & E.B. Almeida, 501 & Fan & & & $\mathrm{x}$ \\
\hline Myrciaria floribunda (H. West ex Willd.) O. Berg & E.B. Almeida, 415 & Fan & & & $\mathrm{x}$ \\
\hline Psidium guineense $\mathrm{Sw}$. & E.B. Almeida, 435 & Fan & $\mathrm{x}$ & & \\
\hline \multicolumn{6}{|l|}{ NYCTAGINACEAE } \\
\hline Guapira nitida (Schmidt) Lundell & E.B. Almeida, 383 & Fan & & & $\mathrm{x}$ \\
\hline \multicolumn{6}{|l|}{ OCHNACEAE } \\
\hline Ouratea fieldingiana (Gardner) Engl. & E.B. Almeida, 372 & Fan & & & $\mathrm{x}$ \\
\hline \multicolumn{6}{|l|}{ OLACACEAE } \\
\hline Ximenia americana $\mathrm{L}$. & E.B. Almeida, 429 & Fan & & & $\mathrm{x}$ \\
\hline \multicolumn{6}{|l|}{ ONAGRACEAE } \\
\hline Ludwigia suffruticosa Walter & M.A. Olivo, 72 & Ter & & $\mathrm{x}$ & \\
\hline \multicolumn{6}{|l|}{ ORCHIDACEAE } \\
\hline Catasetum macrocarpum Rich. ex Kunth & E.B. Almeida, 715 & Epf & & & $\mathrm{x}$ \\
\hline Dimerandra emarginata (G. Mey.) Hoehne & E.B. Almeida, 716 & Epf & & & $\mathrm{x}$ \\
\hline Encyclia acuta Schltr. & E.B. Almeida, 714 & Epf & & & $\mathrm{x}$ \\
\hline Epidendrum schomburgkii Lindl. & E.B. Almeida, 709 & Epf & & & $\mathrm{x}$ \\
\hline Oeceoclades maculata (Lindl.) Lindl. & M.A. Olivo, 141 & Ter & & & $\mathrm{x}$ \\
\hline Polystachya concreta (Jacq.) Garay \& H.R. Sweet & E.B. Almeida, 713 & Epf & & & $\mathrm{x}$ \\
\hline Prosthechea fragrans (Sw.) W.E. Higgins & E.B. Almeida, 712 & Epf & & & $\mathrm{x}$ \\
\hline Vanila chamissonis Klotzsch & E.B. Almeida, 725 & Epf & & & $\mathrm{x}$ \\
\hline Vanila sp. & E.B. Almeida, 711 & Epf & & & $\mathrm{x}$ \\
\hline \multicolumn{6}{|l|}{ PASSIFLORACEAE } \\
\hline Passiflora galbana Mast. & E.B. Almeida, 452 & $\operatorname{Trp}$ & $\mathrm{x}$ & & $\mathrm{x}$ \\
\hline \multicolumn{6}{|l|}{ POACEAE } \\
\hline Andropogon bicornis L. & M.A. Olivo, 117 & Crp & $\mathrm{x}$ & $\mathrm{x}$ & \\
\hline Aristida longifolia Trinx & M.A. Olivo, 130 & Ter & $\mathrm{x}$ & & \\
\hline Eragrostis ciliaris (L.) R. Br. & M.A. Olivo, 94 & Ter & $\mathrm{x}$ & $\mathrm{x}$ & \\
\hline E. rufescens Schrad ex Schult. & M.A. Olivo, 140 & Ter & $\mathrm{x}$ & & \\
\hline Gymnopogon foliosus (Willd.) Nees & M.A. Olivo, 40 & Ter & $\mathrm{x}$ & & \\
\hline Hyparrhenia diplandra (Hack.) Stapf & M.A. Olivo, 124 & Ter & $\mathrm{x}$ & & \\
\hline Panicum laxum $\mathrm{Sw}$. & M.A. Olivo, 137 & Crp & $\mathrm{x}$ & $\mathrm{x}$ & \\
\hline P. pilosum $\mathrm{Sw}$ & M.A. Olivo, 102 & Crp & $\mathrm{x}$ & & \\
\hline Pappophorum mucronulatum Nees & M.A. Olivo, 93 & Ter & $\mathrm{x}$ & & \\
\hline Paspalum arundinaceum Poir. & M.A. Olivo, 136 & $\mathrm{Hmc}$ & $\mathrm{x}$ & $\mathrm{x}$ & \\
\hline P. maritimum Trin. & E.B. Almeida, 445 & $\mathrm{Hmc}$ & $\mathrm{x}$ & $\mathrm{x}$ & \\
\hline Setaria vulpiseta (Lam.) Roem. \& Schult. & M.A. Olivo, 118 & Crp & $\mathrm{x}$ & & \\
\hline Urochloa decumbens (Stapf) R.D. Webster & M.A. Olivo, 127 & Crp & $\mathrm{x}$ & & \\
\hline \multicolumn{6}{|l|}{ POLYGALACEAE } \\
\hline Polygala violacea Aubl. & M.A. Olivo, 18 & Ter & $\mathrm{x}$ & & $\mathrm{x}$ \\
\hline \multicolumn{6}{|l|}{ POLYGONACEAE } \\
\hline Coccoloba confusa How & E.B. Almeida, 459 & Fan & & & $\mathrm{x}$ \\
\hline C. laevis Casar. & E.B. Almeida, 442 & Fan & & & $\mathrm{x}$ \\
\hline C. scandens Casar. & E.B. Almeida, 351 & Fan & & & $\mathrm{x}$ \\
\hline \multicolumn{6}{|l|}{ RUBIACEAE } \\
\hline Borreria verticillata (L.) G. Mey & M.A. Olivo, 38 & Cam & $\mathrm{x}$ & $\mathrm{x}$ & $\mathrm{x}$ \\
\hline B. virgata $(\mathrm{R} . \&$ S.) Schum & M.A. Olivo, 100 & Cam & $\mathrm{x}$ & & \\
\hline Guettarda platypoda DC. & E.B. Almeida, 380 & Fan & & & $\mathrm{x}$ \\
\hline Mitracarpus frigidus (Willd.) K. Schum. & M.A. Olivo, 126 & Cam & $\mathrm{x}$ & $\mathrm{x}$ & \\
\hline Psychotria bahiensis DC. & E.B. Almeida, 516 & Fan & & & $\mathrm{x}$ \\
\hline Psychotria sp. & E.B. Almeida, 407 & Fan & & & $\mathrm{x}$ \\
\hline Richardia grandiflora (Cham. \& Schltdl.) Steud. & E.B. Almeida, 727 & Cam & $\mathrm{x}$ & & \\
\hline Staelia galioides DC. & E.B. Almeida, 406 & Cam & $\mathrm{x}$ & $\mathrm{x}$ & \\
\hline Tocoyena sellowiana (Cham. \& Schltdl.) K. Schum. & E.B. Almeida, 693 & Fan & $\mathrm{x}$ & & \\
\hline \multicolumn{6}{|l|}{ RUTACEAE } \\
\hline Pilocarpus pauciflorus A. St.-Hil. & E.B. Almeida, 373 & Fan & & & $\underset{\mathrm{x}}{\mathrm{x}}$ \\
\hline
\end{tabular}


Tabela 1 (continuação)

\begin{tabular}{|c|c|c|c|c|c|}
\hline \multirow[t]{2}{*}{ Famílias/Espécies } & \multirow[t]{2}{*}{ Coletor/Número } & \multirow[t]{2}{*}{ Forma de vida } & \multicolumn{3}{|c|}{ Fisionomia } \\
\hline & & & $\mathrm{CNI}$ & $\mathrm{CI}$ & FNI \\
\hline \multicolumn{6}{|l|}{ SAPINDACEAE } \\
\hline Cupania racemosa (Vell.) Radlk. & E.B. Almeida, 498 & Fan & & & $\mathrm{X}$ \\
\hline Paullinia trigonia Vell. & E.B. Almeida, 455 & $\operatorname{Trp}$ & & & $\mathrm{x}$ \\
\hline Serjania salzmanniana Schledit & E.B. Almeida, 551 & $\operatorname{Trp}$ & & & $\mathrm{X}$ \\
\hline \multicolumn{6}{|l|}{ SAPOTACEAE } \\
\hline Manilkara salzmannii (A. DC.) H.J. Lam & E.B. Almeida,369 & Fan & & & $\mathrm{x}$ \\
\hline Pouteria sp. & E.B. Almeida, 342 & Fan & & & $\mathrm{X}$ \\
\hline \multicolumn{6}{|l|}{ SCROPHULARIACEAE } \\
\hline Scoparia dulcis L. & M.A. Olivo, 51 & Cam & $\mathrm{x}$ & & \\
\hline Stemodia foliosa Benth. & M.A. Olivo, 65 & Cam & $\mathrm{X}$ & & \\
\hline \multicolumn{6}{|l|}{ SIMAROUBACEAE } \\
\hline Simaba cuneata A. St.-Hil. \& Tul. & E.B. Almeida, 386 & Fan & $\mathrm{x}$ & & $\mathrm{x}$ \\
\hline \multicolumn{6}{|l|}{ SOLANACEAE } \\
\hline Cyphomandra fragrans (Hook.) Sendtn. & E.B. Almeida, 424 & Fan & & & $\mathrm{x}$ \\
\hline Schwenkia americana L. & E.B. Almeida, 699 & Ter & $\mathrm{x}$ & & \\
\hline \multicolumn{6}{|l|}{ STERCULIACEAE } \\
\hline Waltheria indica $\mathrm{L}$. & M.A. Olivo, 70 & Cam & $\mathrm{x}$ & $\mathrm{X}$ & $\mathrm{x}$ \\
\hline W. viscosissima $\mathrm{L}$. & E.B. Almeida, 552 & Cam & $\mathrm{x}$ & & \\
\hline \multicolumn{6}{|l|}{ TURNERACEAE } \\
\hline Turnera ulmifolia L. & E.B. Almeida, 698 & Cam & $\mathrm{X}$ & & \\
\hline \multicolumn{6}{|l|}{ VERBENACEAE } \\
\hline Lantana camara $\mathrm{L}$ & M.A. Olivo, 50 & Fan & $\mathrm{X}$ & & $\mathrm{X}$ \\
\hline Stachytarpheta cayennensis (Rich.) Vahl & M.A. Olivo, 36 & Fan & & & $\mathrm{x}$ \\
\hline
\end{tabular}

Os gêneros com maior número de espécies foram: Chamaecrista (cinco espécies), Inga (quatro), Coccoloba, Cyperus, Eugenia e Myrcia (três). As espécies Andira nitida, Protium heptaphyllum, Sacoglottis mattogrossensis, Chamaecrista ensiformis, Guettarda platypoda, Eugenia hirta, Myrcia bergiana, Casearia javitensis, Coccoloba laevis, Stigmaphyllon paralias, Cuphea flava, Borreria verticillata, Stylosanthes viscosa, Rhynchospora barbata, Paspalum maritimum e Anthurium affine apresentaram elevado número de indivíduos em toda a área.

$\mathrm{Na}$ restinga de Maracaípe, não foi encontrada nenhuma espécie endêmica e $70 \%$ das espécies possuem registro em outras restingas do Nordeste, conforme os levantamentos florísticos realizados (Esteves 1980; Freire 1990; Cabral-Freire \& Monteiro 1993; Oliveira Filho \& Carvalho 1993; Matias \& Nunes 2001; Meira Neto et al. 2005; Sacramento et al. 2007; Silva et al. 2008). As espécies abaixo são citadas pela primeira vez para as restingas de Pernambuco: Annona crassiflora, Byrsonima riparia, Coccoloba confusa, Cryptanthus burle-marxii, Cyphomandra fragrans, Hohenbergia ramageana, Inga flagelliformis, Licania rigida, Marlierea regeliana, Myrcia hirtiflora, Myrciaria floribunda, Ocotea duckei, Pilocarpus pauciflorus, Portea leptantha, Ruellia geminiflora e Sloanea guianensis.

Onze espécies foram comuns às três fisionomias; 14 espécies foram comuns apenas entre as duas fisionomias de campo; 97 espécies foram exclusivas da floresta não inundável; 41 espécies exclusivas do campo não inundável e apenas quatro espécies foram exclusivas do campo inundável (Tab. 1).

As formas de vida que mais se destacaram, no total de espécies, foram os fanerófitos (46\%), seguidos de caméfitos (14\%) e terófitos (12\%) (Fig. 1). Entre os fanerófitos, 44\% (38 espécies) correspondem a mesofanerófitos, na fisionomia floresta não inundável, onde se destacaram Andira nitida, Chamaecrista ensiformis, Protium heptaphyllum, Sacoglottis mattogrossensis e Inga flageliformis. O campo não inundável apresentou maior número de camefítos (25\%), representados por Cuphea flava, Stigmaphyllon paralias, Stylosanthes viscosa, Staelia galioides e Borreria

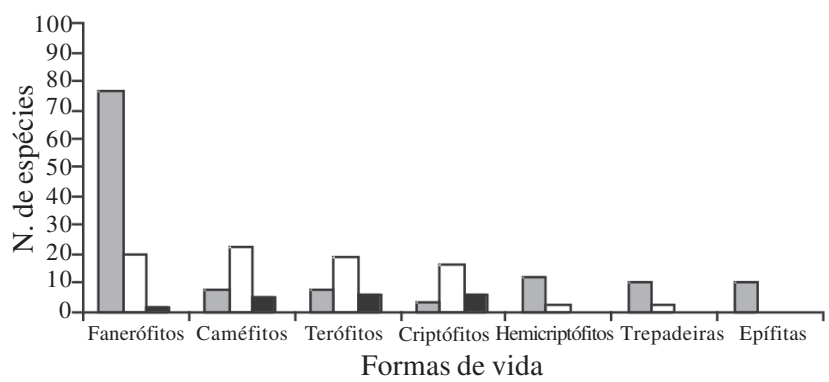

Figura 1. Distribuição das espécies segundo as formas de vida em cada fisionomia da restinga da RPPN, Nossa Senhora do Outeiro de Maracaípe, Ipojuca, PE, Brasil. FNI = floresta não inundável; $\mathrm{CNI}=$ Campo não inundável e CI = Campo inundável. $(\square=\mathrm{FNI}$; $\square=\mathrm{CNI} ; \mathbf{\square}=\mathrm{CI}$ ). 
verticillata; seguidas por terófitos (21\%), destacando-se Conyza bonariensis, Chamaecrista flexuosa, Chamaecrista ramosa, Polygala violacea, Schwenkia americana e Eragrostis ciliaris. No campo inundável, também foram observadas as formas de vida caméfitos e terófitos, porém representadas pelas espécies Bulbostylis capillaris, Eragrostis ciliaris, Paspalum maritimum e Rynchospora riparia.

A floresta não inundável apresentou uma grande diversidade de fanerófitos de grande porte, citadas anteriormente e no interior da fisionomia, destacaram-se como emergentes (15-20 m alt.) os mesofanerófitos Buchenavia capitata, Tapirira guianensis, Manilkara salzmannii e Sloanea guianensis. Essas espécies também ocorreram nas bordas, mas foram mais marcantes no interior da fisionomia, cujo dossel apresentava em média $12 \mathrm{~m}$ alt. Populações de hemicriptófitos, representados principalmente por Aechmea tomentosa, Cryptanthus burle-marxii e Hohenbergia ramageana (Bromeliaceae), também foram encontradas na fisionomia, além de epífitos das famílias Orchidaceae e Araceae. Ainda nessa fisionomia, foi registrado um segundo estrato, constituído pelos microfanerófitos (2-4 m alt.) Casearia javitensis, Myrcia bergiana, Marlierea regeliana e Maytenus distichophylla, e por espécies jovens de mesofanerófitos. Populações de Tetracera breyniana, Coccoloba laevis e Coccoloba scandens ocorrem de forma aglomerada, tornando a fisionomia mais fechada. Nos trechos mais abertos (clareiras), foi notável a colonização de Stigmaphyllon paralias, que atingia até $2 \mathrm{~m}$ alt. As espécies Anacardium occidentale e Hancornia speciosa eram observadas nas bordas e quando presentes no interior do fragmento, ocorriam em locais com indícios de antropização. As espécies Casearia javitensis e Sacoglottis mattogrossensis apresentaram maior intensidade de corte.

No campo não inundável, os indivíduos apresentaram altura média de $50 \mathrm{~cm}$, desenvolvendo-se em solos com pouca quantidade de matéria orgânica. Os caméfitos foram mais abundantes, seguidos dos terófitos, criptófitos e hemicriptófitos, que também contribuíram na composição dessa fisionomia. Rhynchospora riparia (Cyperaceae) e Paspalum maritimum (Poaceae) formavam populações mais numerosas nos trechos de relevo mais ondulados. Indivíduos lenhosos, quando presentes no campo, ocorriam isolados ou em pequenas moitas nas partes planas.

A fisionomia campo inundável ocorreu adjacente ao campo não inundável. O lençol freático do campo inundável chegou a atingir cerca de $0,8 \mathrm{~m}$ alt. acima do nível do solo (Fig. 2) e os indivíduos apresentaram altura inferior a $50 \mathrm{~cm}$. Nessa área, foram detectadas as mais altas taxas de $\mathrm{P}$ e $\mathrm{Fe}$, embora não diferindo

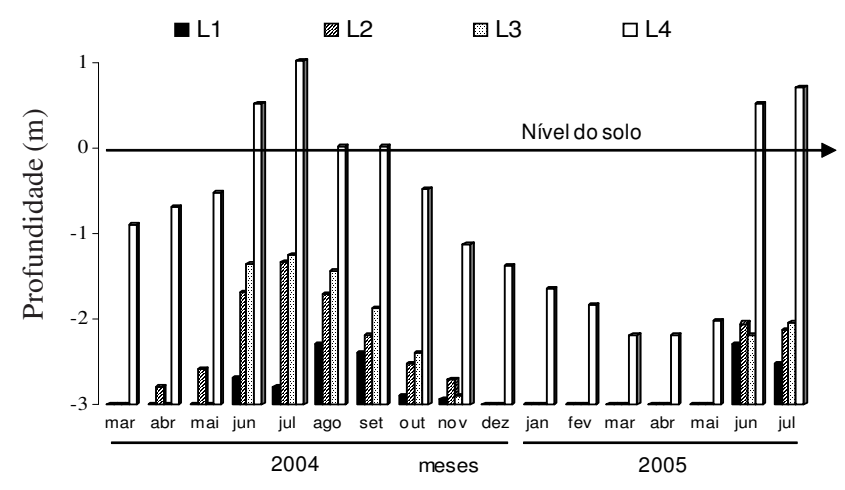

Figura 2. Nível mensal (março/2004 a julho/2005) do lençol freático, em metros, dos quatro poços (L1, L2, L3 presentes na fisionomia floresta não inundável e L4 na fisionomia campo inundável) na restinga da RPPN, Nossa Senhora do Outeiro de Maracaípe, Ipojuca, PE, Brasil.

significativamente das outras fisionomias (Tab. 2). Entre as formas de vida presentes nesta fisionomia, destacamse os caméfitos Cuphea flava e Borreria verticillata, além de espécies de Poaceae e Cyperaceae. Pycreus pelophylus, Ludwigia suffruticosa, Utricularia pusilla e Hydrolea spinosa foram observadas exclusivamente nessa fisionomia.

Durante o monitoramento, constatou-se movimentação do lençol freático nos quatro pontos (L1, L2, L3 e L4), com maior dinâmica no período chuvoso (Fig. 2). Apenas no ponto L4 (campo inundável) houve o afloramento do lençol freático, formando uma lâmina de água sobre o solo. Nos testes não-paramétricos realizados entre os pontos, apenas o ponto do campo inundável mostrou-se significativamente diferente dos outros localizados na floresta, devido ao afloramento do lençol $(\mathrm{L} 1=\mathrm{L} 2=\mathrm{L} 3 \neq \mathrm{L} 4 ; \mathrm{p}<0,001 ; \mathrm{H}=24,9803 ;$ g.l. $=2)$.

Os solos foram classificados como Neossolos Quartzarênicos (Embrapa 1999) e apresentaram teores de areia variando de $98 \%$ a $100 \%$ sem diferença significativa entre a floresta e o campo; já o cascalho apresentou diferença significativa entre as fisionomias (Tab. 2). O $\mathrm{pH}$ do solo em todas as fisionomias foi considerado ácido (variando de 4,4 a 6,3) e as concentrações de $\mathrm{Mg}, \mathrm{P}$, $\mathrm{Ca}^{+}, \mathrm{Al}, \mathrm{T}$ e m (Tab. 2) foram consideradas baixas, de acordo com os critérios de Oleynik (1980). O teor de M.O. variou entre $9,27 \%$ a $44,04 \%$ na floresta; $1,22 \%$ a $4,72 \%$ no campo não inundável, e 3,06\% a $10,19 \%$ no campo inundável, e os valores de $\mathrm{Ca}, \mathrm{C}, \mathrm{H}+\mathrm{Al}, \mathrm{PST}, \mathrm{S}$, $\mathrm{T}, \mathrm{V}, \mathrm{m}$ e matéria orgânica, apresentaram diferenças significativas entre as fisionomias (Tab. 2), contribuindo para a diferenciação na composição das espécies em cada formação fisionômica.

\section{Discussão}

As famílias de maior riqueza de espécies da flora da restinga de Maracaípe foram similares às registradas para 
Tabela 2. Médias das variáveis químicas e granulométricas do solo nos diferentes tipos fisionômicos da restinga RPPN, Nossa Senhora do Outeiro de Maracaípe, Ipojuca, PE, Brasil ( $\pm=$ desvio padrão; ns = diferença não significativa; letras minúsculas diferentes seguidas em uma mesma linha indicam diferença estatística pelo teste Mann-Whitney, a 5\%).

\begin{tabular}{|c|c|c|c|}
\hline Variáveis químicas & Floresta fechada não inundável & Campo não inundável & Campo inundável \\
\hline $\mathrm{pH}\left(\mathrm{H}_{2} \mathrm{O}\right)$ & $4,58 \pm 0,70 \mathrm{~ns}$ & $4,94 \pm 0,33 \mathrm{~ns}$ & $5,90 \pm 0,45 \mathrm{~ns}$ \\
\hline M.O. - matéria orgânica (g/kg) & $28,80 \pm 17,37 \mathrm{a}$ & $3,72 \pm 1,45 b$ & $5,26 \pm 2,84 b$ \\
\hline $\mathrm{P}(\mathrm{mg} / \mathrm{dm} 3)$ & $3,41 \pm 0,97 \mathrm{~ns}$ & $1,68 \pm 0,62 \mathrm{~ns}$ & $9,9 \pm 15,77 \mathrm{~ns}$ \\
\hline $\mathrm{C}(\mathrm{g} / \mathrm{Kg})$ & $16,70 \pm 10,08 \mathrm{a}$ & $2,16 \pm 0,84 b$ & $3,05 \pm 1,65 b$ \\
\hline $\mathrm{H}^{+}+\mathrm{Al}^{+++}\left(\mathrm{cmol}_{\mathrm{c}} / \mathrm{dm}^{3}\right)$ & $3,17 \pm 2,82 \mathrm{a}$ & $0,41 \pm 0,12 b$ & $0,50 \pm 0,30 \mathrm{~b}$ \\
\hline $\mathrm{Na}\left(\mathrm{cmol}_{\mathrm{c}} / \mathrm{dm}^{3}\right)$ & $0,06 \pm 0,02 \mathrm{~ns}$ & $0,05 \pm 0,04 \mathrm{~ns}$ & $0,08 \pm 0,03 \mathrm{~ns}$ \\
\hline $\mathrm{K}^{+}\left(\mathrm{cmol}_{\mathrm{c}} / \mathrm{dm}^{3}\right)$ & $0,07 \pm 0,06 \mathrm{~ns}$ & $0,07 \pm 0,06 \mathrm{~ns}$ & $0,13 \pm 0,13 \mathrm{~ns}$ \\
\hline $\mathrm{Ca}^{++}\left(\mathrm{cmol}_{\mathrm{c}} / \mathrm{dm}^{3}\right)$ & $0,72 \pm 0,40 \mathrm{a}$ & $0,25 \pm 0,17 b$ & $0,57 \pm 0,28 b$ \\
\hline $\mathrm{Mg}^{++}\left(\mathrm{cmol}_{\mathrm{c}} / \mathrm{dm}^{3}\right)$ & $0,55 \pm 0,39 \mathrm{~ns}$ & $0,10 \pm 0,07 \mathrm{~ns}$ & $0,18 \pm 0,15 \mathrm{~ns}$ \\
\hline $\mathrm{Al}^{+++}\left(\mathrm{cmol}_{\mathrm{c}} / \mathrm{dm}^{3}\right)$ & $0,40 \pm 0,62 \mathrm{~ns}$ & $0,15 \pm 0,10 \mathrm{~ns}$ & $0,05 \pm 0,05 \mathrm{~ns}$ \\
\hline $\mathrm{Fe}\left(\mathrm{cmol}_{\mathrm{c}} / \mathrm{dm}^{3}\right)$ & $3,20 \pm 0,52 \mathrm{~ns}$ & $9,83 \pm 10,14 \mathrm{~ns}$ & $13,42 \pm 10,28 \mathrm{~ns}$ \\
\hline $\operatorname{Mn}\left(\mathrm{cmol}_{\mathrm{c}} / \mathrm{dm}^{3}\right)$ & $1,90 \pm 2,08 \mathrm{~ns}$ & $3,54 \pm 4,82 \mathrm{~ns}$ & $0,20 \pm 0,28 \mathrm{~ns}$ \\
\hline $\mathrm{Zn}\left(\mathrm{cmol}_{\mathrm{c}} / \mathrm{dm}^{3}\right)$ & $2,61 \pm 3,63 \mathrm{~ns}$ & $3,54 \pm 4,82 \mathrm{~ns}$ & $2,91 \pm 1,81 \mathrm{~ns}$ \\
\hline $\mathrm{Cu}\left(\mathrm{cmol}_{\mathrm{c}} / \mathrm{dm}^{3}\right)$ & 0,00 & 0,00 & 0,00 \\
\hline $\mathrm{S}$ - soma de bases $\left(\mathrm{cmol}_{\mathrm{c}} / \mathrm{dm}^{3}\right)$ & $1,40 \pm 0,53 a$ & $0,47 \pm 0,26 b$ & $0,96 \pm 0,24 b$ \\
\hline $\mathrm{T}$ - capacidade de troca catiônica $\left(\mathrm{cmol}_{\mathrm{c}} / \mathrm{dm}^{3}\right)$ & $4,57 \pm 3,09 a$ & $0,88 \pm 0,33 b$ & $1,46 \pm 0,47 b$ \\
\hline $\mathrm{V}$ - saturação de bases $(\%)$ & $35,64 \pm 13,55 \mathrm{a}$ & $50,54 \pm 16,38 \mathrm{ab}$ & $67,21 \pm 10,92 b$ \\
\hline m - saturação por alumínio (\%) & $16,47 \pm 18,22 \mathrm{a}$ & $22,90 \pm 4,65 b$ & $5,61 \pm 6,06 a$ \\
\hline PST - percentagem de sódio trocável $(\%)$ & $1,96 \pm 1,26 \mathrm{a}$ & $6,55 \pm 5,85 b$ & $6,31 \pm 3,24 b$ \\
\hline Areia $(\%)$ & $98,73 \pm 1,39 \mathrm{~ns}$ & $99,74 \pm 0,36 \mathrm{~ns}$ & $99,02 \pm 0,87 \mathrm{~ns}$ \\
\hline Cascalho $(\%)$ & $1,27 \pm 1,39 \mathrm{ab}$ & $0,26 \pm 0,30 \mathrm{a}$ & $0,98 \pm 0,87 \mathrm{~b}$ \\
\hline Silte $(\%)$ & 0,00 & 0,00 & 0,00 \\
\hline $\operatorname{Argila}(\%)$ & 0,00 & 0,00 & 0,00 \\
\hline
\end{tabular}

outras áreas de restingas do Nordeste (Esteves 1980; Oliveira Filho \& Carvalho 1993; Cabral-Freire \& Monteiro 1993; Matias \& Nunes 2001; Sacramento et al. 2007) e diferem do encontrado no Sudeste e Sul, onde as famílias Bromeliaceae, Melastomataceae, Mimosaceae, Asteraceae, Apiaceae, Salicaceae e Convolvulaceae apresentam maior diversidade (Araujo \& Henriques 1984; Sá 1992; Menezes \& Araujo 1999; Dorneles \& Waechter 2004; Souza et al. 1991/1992).

O número de gêneros com uma única espécie na restinga de Maracaípe foi elevado e 70\% das espécies apresentaram registro de ocorrência em outros levantamentos florísticos das restingas da região (Andrade-Lima 1979; Esteves 1980; Pinto et al. 1984; Freire 1990; Oliveira Filho \& Carvalho 1993; CabralFreire \& Monteiro 1993; Matias \& Nunes 2001; Meira Neto et al. 2005; Zickel et al. 2007), mostrando que a flora da restinga nordestina é relativamente semelhante. Vale ainda comentar que algumas das espécies referidas para a vegetação de restinga também ocorrem em formações vegetacionais adjacentes, como Floresta Ombrófila Densa de Terras Baixa e Floresta Ombrófila Montana do Nordeste, indicando, por um lado, que a proximidade entre formações influencia a composição florística das áreas, como já observado para o Sudeste (Pereira \& Araujo 2000; Cerqueira 2000; Scarano et al. 2004), e por outro, que as restingas do Nordeste talvez não apresentem um conjunto típico e ou exclusivo de espécies que as possam caracterizar (Zickel et al. 2004).

Apesar de não ter sido possível identificar um grupo de espécies exclusivas na restinga de Maracaípe, algumas das famílias como Orchidaceae, Cyperaceae, Poaceae e Myrtaceae merecem destaque pela diversidade de espécies com que se fizeram presentes na área. A família Orchidaceae tem sido considerada como um indicativo biológico do bom estado de conservação dos habitats (Budowski 1965) e sua dispersão é facilitada pelo pequeno tamanho dos diásporos das espécies (Nunes \& Waechter 1998; Gonçalves \& Waechter 2003). Essa família também se destaca na floresta Atlântica e nos ecossistemas associados (Borgo \& Silva 2003). Já a riqueza de Cyperaceae e Poaceae pode estar sendo facilitada por estas famílias possuírem muitas espécies heliófitas, que apresentam maior habilidade para se estabelecer em fisionomias abertas e com baixo nível de sombreamento, bem como por apresentarem propagação vegetativa e ou dispersão e polinização facilitada pelo vento (Cabral-Freire \& Monteiro 1993), com grande produção de sementes para renovação do estoque do banco do solo (Whitmore 1988; Bond \& Wilgen 1996).

No Sudeste, uma das fisionomias de restinga é designada por thicket de Myrtaceae, devido à frequência das espécies desta família na área (Araujo \& Henriques 1984). Todavia, em Maracaípe, apesar de Myrtaceae 
apresentar elevada riqueza, suas espécies não formavam populações abundantes, não se destacando na fisionomia.

Nas restingas nordestinas, a forma de vida fanerófito apresenta frequência elevada apenas na fisionomia floresta (Meira Neto et al. 2005; J.R. Cantarelli, dados não publicados). Ao se considerar outras fisionomias, as formas caméfitos, terófitos e criptófitos apresentam percentuais superiores aos de fanerófitos (Sacramento et al. 2007; Silva et al. 2008), fato este também encontrado no presente estudo. Todavia, tal tendência diverge do registrado por D.S.D. Araujo (dados não publicados) para as restingas do Rio de Janeiro, onde não existem diferenças nas freqüências de formas de vida. Vale salientar que a autora considerou o hábito (árvore, arbusto, erva, liana e epífita) como separador das formas de vida, o que difere do proposto no sistema de Raunkiaer (1934), aqui adotado, que se baseia no grau de proteção conferido às gemas da planta para sobreviver em estação desfavorável. Isto permite reconhecer que um mesmo hábito (por exemplo, ervas) pode ser representado por diferentes formas de vida (fanerófito, hemicriptófico, caméfito, criptófito e terófito). Como o sistema de Raunkiaer vem sendo adotado nas restingas do Nordeste, formas de vida têm se mostrado uma variável importante para individualizar fisionomias na restinga.

Nas fisionomias das restingas do Sudeste algumas espécies apresentam arranjo em moitas, como ocorre com espécies da família Bromeliaceae, que atualmente vem sendo considerada como um grupo biológico facilitador do processo sucessional e da diversidade local, por melhorar as condições nutricionais do solo (Hay \& Lacerda 1984; Zaluar \& Scarano 2000) e disponibilizar sítios favoráveis à germinação de outras espécies (Fialho \& Furtado 1993). Todavia, as espécies das fisionomias estudadas em Maracaípe não apresentaram arranjo em moitas, e o papel ecológico de bromeliáceas na melhoria das condições de sítios para o estabelecimento de outras espécies não foi percebido. Contudo, Siqueira Filho \& Machado (1998) destacaram que espécies da família Bromeliaceae disponibilizam recursos florais que são atrativos para a fauna. Logo, o papel funcional das bromeliáceas como facilitadoras da diversidade local na área de estudo, pode está ocorrendo através das interações biológicas (planta-animal), atraindo possíveis polinizadores de outras espécies do ecossistema.

Outros fatores que contribuem para a diferenciação das fisionomias na restinga são os teores de nutrientes do solo e o lençol freático. A variação do lençol freático influencia o conjunto florístico que pode se estabelecer em cada microhabitat (Pereira et al. 1992; Sá 1992). De acordo com Sá (1992), quando o lençol freático ocorre mais próximo da superfície do solo, a diversidade de espécies do estrato herbáceo é elevada, nas fisionomias de campo. Neste estudo, a diversidade de herbáceas foi elevada apenas no campo não inundável. Já no campo inundável, apenas espécies com aptidão para sobreviver em locais encharcados estabeleceram-se, tornando a diversidade reduzida.

Registrou-se que as espécies respondem de maneira diferente à variação dos teores de nutrientes do solo (Silva Jr. et al. 1987; Moreno \& Schiavini 2001). Entre as variáveis analisadas no presente estudo, a matéria orgânica merece maior destaque, pois sua presença modifica a estrutura de solos arenosos, aumenta a agregação das partículas e a absorção de nutrientes, aumenta a retenção de umidade e oferece maior sustentabilidade ao desenvolvimento das espécies arbóreas (Moniz 1975; Silva \& Somner 1984; Wutke 1972). Na restinga de Maracaípe, a matéria orgânica e o teor de alumínio e de bases, juntamente com a disponibilidade de água do lençol freático, contribuíram para a diferenciação encontrada nas fisionomias. Essas relações também foram apontadas por Cestaro \& Soares (2004), que indicaram fertilidade, teor de alumínio e regime hídrico dos solos como os principais elementos que, possivelmente, determinam as pequenas diferenças florística e estrutural da vegetação.

Este estudo permitiu concluir que as variações no nível do lençol freático e nas características químicas do solo foram fatores determinantes de diferenças nas composições florísticas e fisionômicas da vegetação em ambientes de restinga.

\section{Agradecimentos}

Ao CNPq, pela concessão das bolsas de estudo do primeiro autor e de produtividade do terceiro autor (proc. 301147/2004-3) e pelo financiamento do projeto "Aspectos Florísticos, Anatômicos e Ecológicos da vegetação da Restinga da RPPN Nossa Senhora do Outeiro de Maracaípe, Ipojuca, Pernambuco" (proc. 473974/03-2), coordenado pela Profa. Dra. Carmen Silvia Zickel; aos especialistas de várias famílias que confirmaram e identificaram grande parte do material. A todos os colegas que ajudaram direta ou indiretamente na execução deste trabalho, em especial a Daniel Medeiros, José Urbano, James Cantarelli e Adriano Vicente; aos revisores pelas sugestões.

\section{Referências bibliográficas}

Andrade-Lima, D. 1951. A flora da praia de Boa Viagem. Pp. 121-125. In: Separata do Boletim da SAIC 18. Recife.

Andrade-Lima, D. 1954. Primeira contribuição para o conhecimento da flora do Cabo de Santo Agostinho. Pp.48-57. In: Separata de Anais do IV Congresso Nacional da Sociedade Botânica do Brasil. Recife. 
Andrade-Lima, D. 1960. Estudos fitogeográficos de Pernambuco. Instituto de Pesquisa Agronômica de Pernambuco. v.2. Recife.

Andrade-Lima, D. 1979. A flora e a vegetação da área Janga Maranguape/ Paulista - Pernambuco. Pp. 179-190. In: Anais do Congresso Nacional de Botânica, 30. Campo Grande. Sociedade Brasileira de Botânica.

Araujo, D.S.D. \& Henriques, R.P.B. 1984. Análise florística das restingas do Estado do Rio de Janeiro. Pp. 47-60. In: L.D. Lacerda; D.S.D. Araujo; R. Cerqueira \& B. Turq (eds.). Restingas: Origem, Estrutura e Processos. Niterói, CEUFF.

Assis, A.M.; Thomaz, L.D. \& Pereira, O.J. 2004. Florística de um trecho de floresta de restinga no município de Guarapari, Espírito Santo, Brasil. Acta Botanica Brasilica 18: 191-201.

Ayres, M.; Ayres Junior, M.; Ayres, D.L. \& Santos, A. 2000. BioEsta 2.0: Aplicações estatísticas nas áreas de ciências biológicas e médicas. $2^{\text {a }}$ ed. Belém, Sociedade Civil Mamirauá, CNPq.

Barreto, R.C. 2002. A família Commelinaceae R. Br. No Estado de Pernambuco. Pp. 319-329. In: M. Tabarelli \& J.M.C. Silva (orgs.). Diagnóstico da Biodiversidade de Pernambuco. v.1. Recife. Secretaria de Ciência, Tecnologia e Meio Ambiente.

Bond, W.J. \& Wilgen, B.W. van. 1996. Fire and plants. London, Chapman \& Hall. (Population and community biology, 14).

Borgo, M. \& Silva, S.M. 2003. Epífitos vasculares em fragmentos de floresta ombrófila mista, Curitiba, Paraná, Brasil. Revista Brasileira de Botânica 26: 391-401.

Budowski, G. 1965. Distribution of tropical american rainforest species in the light of sucessional processes. Turrialba 15: 40-42.

Cabral-Freire, M.C.C. \& Monteiro, R. 1993. Florística das praias da Ilha de São Luís, Estado do Maranhão (Brasil): diversidade de espécies e suas ocorrências no litoral brasileiro. Acta Amazonica 23: $125-140$.

Cerqueira, R. 2000. Biogeografia das restingas. Pp. 65-76. In: F.A. Esteves \& L.D. Lacerda (eds.). Ecologia de Restingas e Lagoas Costeiras. Macaé, UFRJ/ NUPEM.

Cestaro, L.A. \& Soares, J.J. 2004. Variações florística e estrutural e relações fitogeográficas de um fragmento de floresta decídua no Rio Grande do Norte, Brasil. Acta Botanica Brasilica 18: 203-218.

Cronquist, A. 1988. The evolution and classification of flowering plants. $2^{\text {nd }}$ ed. New York, The New York Botanical Garden.

Dorneles, L.P.P. \& Waechter, J.L. 2004. Fitossociologia do componente arbóreo na floresta turfosa do Parque Nacional da Lagoa do Peixe, Rio Grande do Sul, Brasil. Acta Botanica Brasilica 18: $815-824$.

EMBRAPA. 1997. Manual de Métodos de análise de solo. $2^{\text {a }}$ ed. Rio de Janeiro, Empresa Brasileira de Pesquisa Agropecuária, Centro Nacional de Pesquisa de Solos.

EMBRAPA. 1999. Sistema brasileiro de classificação de solos Rio de janeiro, Empresa Brasileira de Pesquisa Agropecuária, Centro Nacional de Pesquisa de Solos.

Esteves, G.L. 1980. Contribuição ao conhecimento da vegetação da restinga de Maceió - Alagoas. Secretaria de Planejamento do Estado de Alagoas.

Fialho, R.F. \& Furtado, A.L.S. 1993. Germination of Erythroxylum ovalifolium (Erythroxylaceae) seeds within the terrestrial bromeliad Neoregelia cruenta. Biotropica 25: 359-362.

Freire, M.S.B. 1990. Levantamento florístico do Parque Estadual das Dunas de Natal. Acta Botanica Brasilica 4: 41-59.

Furlan, A. \& Machado, P.A. 2002. Molluginaceae. Pp. 187-188. In: M.G.L. Wanderley; G.J. Shepherd \& A.M. Giulietti (coords.). Flora Fanerogâmica do Estado de São Paulo. v.2. São Paulo. FAPESP, HUCITEC.

Gonçalves, C.N. \& Waechter, J.L. 2003. Aspectos florísticos e ecológicos de epífitos vasculares sobre figueiras isoladas no norte da planície costeira do Rio Grande do Sul. Acta Botanica Brasilica 17: 89-100.
Hay, J.D. \& Lacerda, L.D. 1984. Ciclagem de nutrientes do ecossistema de restinga. Pp. 461-477. In: L.D. Lacerda; D.S.D. Araujo; R. Cerqueira \& B. Turq (eds.). Restingas: Origem, Estrutura e Processos. Niterói, CEUFF.

IBAMA 2000. Instituto brasileiro do meio ambiente e dos recursos naturais renováveis. Portaria $\mathrm{N}^{\circ} 58$ de 26 de setembro de 2000. Disponível em: http://www.cprh.pe.gov.br/.

INMET - Instituto Nacional de Meteorologia. 2005. Disponível em www.inmet.gov.br. (Acessado em: 10/01/2005).

Koppen, W. 1948. Climatologia: com un estudio de los climas de la tierra. Mexico, Fondo de Cultura Economica.

Lorenzi, H. 1992. Árvores brasileiras: manual de identificação e cultivo de plantas arbóreas nativas do Brasil. v.1. Nova Odessa, Editora Plantarum.

Lorenzi, H. 1998. Árvores brasileiras: manual de identificação e cultivo de plantas arbóreas nativas do Brasil. v.2. Nova Odessa, Editora Plantarum.

Maas, P.J.M. \& Westra, L.Y.Th. 1992. Rollinia. Flora Neotropica 57: $1-188$.

Martins, F.R. 1991. Estrutura de uma floresta mesófila. Campinas, Universidade Estadual de Campinas.

Matias, L.Q. \& Nunes, E.P. 2001. Levantamento florístico da Área de Proteção Ambiental de Jericoacoara, Ceará. Acta Botanica Brasilica 15: 35-43.

Medeiros, D.P.W.; Lopes, A.V. \& Zickel, C.S. 2007. Phenology of woody species in tropical coastal vegetation, northeastern Brazil. Flora. Flora 202: 513-520.

Meira Neto, J.A.; Souza, A.L.; Lana, J.M. \& Valente, G.E. 2005. Composição florística, espectro biológico e fitofisionomia da vegetação de muçununga nos Municípios de Caravelas e Mucuri, Bahia. Revista Árvore 29: 139-150.

Menezes, L.F.T. \& Araujo, D.S.D. 1999. Estrutura de duas formações vegetais do cordão externo da restinga de Marambaia, Rio de Janeiro. Acta Botanica Brasilica 13: 115-236.

Miranda, E.B. \& Giulietti, A.M. 2001. Eriocaulaceae no Morro do Pai Inácio (Palmeiras) e Serra da Chapadinha (Lençóis), Chapada Diamantina, Bahia, Brasil. Sitientibus (Série Ciências Biológicas) 1: 15-32.

Moniz, A.C. 1975. Elementos de pedologia. São Paulo, Livros Técnicos e Científicos.

Moreno, M.I.C. \& Schiavini, I. 2001. Relação entre vegetação e solo em um gradiente florestal na Estação Ecológica do Panga, Uberlândia (MG.). Acta Botanica Brasilica 24: 537-544.

Mori, L.A.; Silva, L.A.M.; Lisboa, G. \& Coradin, L. 1989. Manual de manejo do herbário fanerogâmico. Ilhéus, Centro de Pesquisa do Cacau.

Nunes, V.F. \& Waechter, J.L. 1998. Florística e aspectos fitogeográficos de Orchidaceae epifíticas de um morro granítico subtropical. Pesquisas 48: 127-162.

Oleynik, J. 1980. Manual de fertilidade e correção dos solos. Curitiba, Associação de Crédito e Assistência Social.

Oliveira Filho, A.T. 1993. Gradient analysis of an area of coastal vegetation in the state of Paraíba, Northeastern Brazil. Edinburgh Journal of Botany 50: 217-236.

Oliveira Filho, A.T. \& Carvalho, D.A. 1993. Florística e fisionomia da vegetação no extremo norte do litoral da Paraíba. Revista Brasileira de Botânica 16: 115-130.

Pereira, O.J. \& Araujo, D.S.D. 2000. Análise florística das restingas dos Estados do Espírito Santo e Rio de Janeiro. Pp. 25-63. In: F.A. Esteves \& L.D. Lacerda (eds.). Ecologia de Restingas e Lagoas Costeiras. Macaé, UFRJ/ NUPEM.

Pereira, O.J.; Thomaz, L.D. \& Araujo, D.S.D. 1992. Fitossociologia da vegetação de antedunas da restinga de Setiba/Guarapari e em Interlagos/Vila Velha, ES. Boletim Museu Biologia Mello Leitão (nova série) 1: 65-75.

Pereira, M.S. \& Barbosa, M.R.V. 2004. A família Rubiaceae na Reserva Biológica Guaribas, Paraíba, Brasil. Subfamílias Antirheoideae, Cinchonoideae e Ixoroideae. Acta Botanica Brasilica 18: 305-318. 
Pinto, G.C.P.; Bautista, H.P. \& Pereira, J.D.C. A. 1984. A restinga do litoral nordeste do Estado da Bahia. Pp. 195-203. In: L.D Lacerda; D.S.D. Araújo; R. Cerqueira \& B. Turq (eds.). Restingas: Origem, Estrutura e Processos. Niterói, CEUFF.

Pontes, A.F.; Barbosa, M.R.V. \& Maas, P.J.M. 2004. Flora Paraibana: Annonaceae Juss. Acta Botanica Brasilica 18: 281-293.

Raunkiaer, C. 1934. The Life Forms of Plants and Statistical Plant Geography. Oxford, Clarendon.

Rodrigues, E.A. \& Rossi, L. 2002. Olacaceae. Pp. 231-217. In: M.G.L. Wanderley; G.J. Shepherd \& A.M. Giulietti (coords.). Flora Fanerogâmica do Estado de São Paulo. v.2. São Paulo, FAPESP, HUCITEC

Sá, C.F.C. 1992. A vegetação da restinga de Ipitangas, Reserva Ecológica Estadual de Jacarepiá, Saquarema (RJ): Fisionomia e Listagem de Angiospermas. Arquivos do Jardim Botânico do Rio de Janeiro 31: 87-102.

Sacramento, A.C.; Zickel, C.S. \& Almeida Jr., E.B. 2007. Aspectos florísticos da vegetação de restinga no litoral de Pernambuco. Revista Árvore 31: 1121-1130.

Scarano, F.R.; Cirne, P.; Nascimento, M.T.; Sampaio, M.C.; Villela, D.M.; Wendt, T. \& Zaluar, H.L.T. 2004. Ecologia vegetal: integrando ecossistemas, comunidades, populações e organismos. Pp. 77-97. In: C.F.D. Rocha; F.A. Esteves \& F.R. Scarano (eds.). Pesquisas de longa duração na restinga de Jurubatiba. Ecologia, história natural e conservação. São Carlos, Rima editora.

Silva, J.G. \& Somner, G.V. 1984. A vegetação da restinga na Barra de Maricá, RJ. Pp. 217-225. In: L.D. Lacerda; D.S.D. Araujo; R. Cerqueira \& B. Turcq (orgs.). Restingas: Origem, Estrutura e Processos. Niterói, CEUFF.

Silva Jr., M.C.; Barros, N.F. \& Cândido, J.F. 1987. Relação entre parâmetros do solo e da vegetação de cerrado na Estação Florestal de Experimentação de Paraopeba, MG. Revista Brasileira de Botânica 10: 125-137.

Silva, S.M. \& Britez, R.M. 2005. A vegetação da Planície Costeira. In: M.C.M. Marques \& R.M. Britez (orgs.). História Natural e conservação da Ilha do Mel. Curitiba, UFPR.

Silva, S.S.L.; Zickel, C.S. \& Cestaro, L.A. 2008. Flora vascular e perfil fisionômico de uma restinga no litoral sul de Pernambuco. Acta Botanica Brasilica 22: 1123-1135.
Siqueira Filho, J.A. \& Machado, I.C. 1998. Biologia floral de Hohenbergia ridleyi (Baker) Mez (Bromeliaceae). Bromelia 5: 3-13.

Skorupa, L.A. 2003. Novos táxons infraespecíficos e combinações em Pilocarpus Vahl (Rutaceae). Revista Brasileira de Botânica 26: 263-270.

Souza, M.L.D.R.; Falkenberg, D.B.; Amaral, L.G.; Fronza, M.; Araujo, A.M. \& Sá, M.R. 1991/1992. Vegetação do pontal da Daniela, Florianópolis, SC, Brasil. I. Levantamento florístico e mapa fitogeográfico. Insula 21: 87-117.

Souza, E.B. \& Sales, M.F. 2004. O gênero Staelia Cham. \& Schltdl. (Rubiaceae - Spermacoceae) no Estado de Pernambuco, Brasil. Acta Botanica Brasilica 18: 919-926.

Suguio, K. \& Tessler, M.G. 1984. Planície de cordões litorâneos quaternários do Brasil: origem e nomenclatura. Pp. 15-25. In: L.D. Lacerda; D.S.D. Araujo; R. Cerqueira \& B. Turq (eds.). Restingas: Origem, Estrutura e Processos. Niterói, CEUFF.

Veloso, H.P. 1992. Manual técnico da vegetação brasileira. Manual técnico em geociências n.1. Rio de Janeiro, IBGEDERMA.

Whitmore, T.C. 1988. Forest dynamics and questions of scala. Pp. 13-17. In: M.E. Hadley. Rain forest Regeneration and Management. Paris, Int. Union of Biology Scence.

Wutke, A.C.P. 1972. Acidez. Pp. 149-168. In: A.C. Moniz (coord.). Elementos de Pedologia. São Paulo, Universidade de São Paulo \& Polígono.

Zaluar, H.L.T. \& Scarano, F.R. 2000. Facilitação em restingas de moitas: Um século de buscas por espécies focais. Pp. 3-23. In: F.A. Esteves \& L.D. Lacerda (eds.). Ecologia de restingas e lagoas costeiras. Rio de Janeiro, NUPEM/UFRJ.

Zickel, C.S.; Vicente, A.; Almeida Jr., E.B.; Cantarelli, J.R.R. \& Sacramento, A.C. 2004. Flora e vegetação das restingas no Nordeste Brasileiro. Pp. 689-701. In: E. Eskinazi-Leça; S. Neumann-Leitão \& M.F. Costa (orgs.). Oceanografia: um cenário tropical. Recife, Bargaço.

Zickel, C.S.; Almeida Jr., E.B.; Medeiros, D.P.W.; Lima, P.B.; Souza, T.M.S. \& Lima, A.B. 2007. Magnoliophyta species of restinga, State of Pernambuco, Brazil. Check List 3: 224-241. 